\title{
Effect of Blanching on Enzyme Activity and Bioactive Compounds of Blackberry
}

\author{
Caciano Zapata Noreña ${ }^{\mathbf{1}^{*}}$, Renata Trindade Rigon ${ }^{\mathbf{1}}$. \\ ${ }^{l}$ Universidade Federal do Rio Grande do Sul - Institute of Food Science and Technology, Porto Alegre, Rio Grande \\ do Sul ,Brazil
}

\begin{abstract}
The inactivation of peroxidase and polyphenol oxidase and the degradation of phenolic compounds, anthocyanins, and antioxidant activity in blackberry were investigated during blanching in water at $80-90{ }^{\circ} \mathrm{C}$, and in steam, from 0 to 10 minutes. The enzyme kinetics indicated the presence of two isoenzymes with different thermal stability, following two-phase model, in which the reaction rate constant increased with increasing temperature for both the heat labile and heat resistant component. The phenolic compounds also followed a biphasic pattern, indicating a more heat resistant fraction, and the rate constants increased with increasing temperature. For the antioxidant activity and anthocyanins, the first order kinetic model $(R 2>0.982)$ indicated an increase in degradation rate constants with temperature, from 0.050 to $0.137 \mathrm{~min}^{-1}$ for DPPH, 0.085 to $0.285 \mathrm{~min}^{-1}$ for ABTS, and 0.017 to 0.052 min $^{-1}$ for anthocyanins.
\end{abstract}

Keywords: peroxidase, polyphenol oxidase, phenolic, anthocyanins.

\footnotetext{
*Author for correspondence: czapatan@ufrgs.br
} 


\section{INTRODUCTION}

Blackberry (Rubus fruticosus) fruit is known as an excellent source of bioactive compounds such as anthocyanins, flavonols, and phenolic acids ${ }^{1}$. These compounds have antioxidant activity by neutralizing free radical, quenching singlet and triplet oxygen, and can also be enzyme inhibitors and act as synergists of other phenolic compounds ${ }^{2}$. The antioxidant activity of blackberry is directly related to its anthocyanins content ${ }^{3}$, and cyanidin-3-glucoside is the most abundant ${ }^{4}$. Anthocyanins also provide health benefits as anti-inflammatory and anticancer effects, reducing the risk of coronary heart disease and preventing chronic diseases ${ }^{5}$. The stability of anthocyanins can be affected by many factors, such as $\mathrm{pH}$, light, oxygen and enzymes ${ }^{6}$ including peroxidase (POD) and polyphenol oxidase (PPO) that are considered the main responsible for the deterioration of fruits and vegetables.

The POD catalyzes the oxidation reactions by the use of peroxide or oxygen as hydrogen acceptor, and its mechanism is based on the formation of complex hydrogen enzyme-donor ${ }^{7}$. The hydrogen donor can be phenols, amines or other organic compounds, and products formed during oxidation ${ }^{8}$. The PPO is a copper containing enzyme that in the presence of oxygen catalyzes the oxidation of phenolic substrates in quinones, which in turn are polymerized in brown, red or black pigments ${ }^{9}$. In addition, the PPO may be responsible for the loss of red color characteristic of some fruits ${ }^{10}$.

Once POD and PPO activities can cause degradation of anthocyanins in fruits ${ }^{10}$, certain treatments are adopted to prevent degradation of these bioactive compounds and to stop the activity of these enzymes. Blanching is a heat treatment to which vegetables and fruits are subjected before processing for the maintenance of quality attributes such as color and texture, with positive effects including destruction of the surface microflora and enzyme inactivation ${ }^{11}$. However, heat treatment may also result in undesirable product changes including nutrient losses, thus a kinetic study is essential to predict the product quality loss during blanching, contributing to select the optimal processing conditions.

It is scarce in the literature information about the integral study of the kinetics of deactivation of enzymes and the loss of quality, such as anthocyanins, polyphenols, and antioxidant activity during heating of blackberry.

The aim of this study was to evaluate the inactivation kinetics of peroxidase and polyphenol oxidase and the degradation kinetics of bioactive compounds during blanching of blackberry.

\section{MATERIAL AND METHODS}

\section{Experimental Procedure}

Blackberries were selected considering the absence of visual damage. The fruit had $10.2{ }^{\circ}$ Brix and $1.3 \%$ of titratable acidity (expressed as malic acid), which were determined with a refractometer (Milwaukee, MA871) at $20{ }^{\circ} \mathrm{C}$, and by titration with $0.1 \mathrm{~mol} / \mathrm{l} \mathrm{NaOH}$, respectively. The samples were washed with potable water and cut into slices $3 \pm 0.3 \mathrm{~mm}$ thick using a food processor (Black and Decker). Then, blanching was carried out in water at temperatures of 80 to $90{ }^{\circ} \mathrm{C}$ in a thermostated bath (Heidolph, Laborota 4000), and in steam environment in an autoclave at atmospheric pressure. When the water bath was used, the samples were placed in a basket and completely immersed in the water, which had previously been heated to the desired temperature. In the case of the autoclave, the samples were also put in the basket inside of the autoclave and then the steam valve was opened. Blanching times 
of $1,2,4,6,8$, and 10 minutes were used, followed by rapid cooling of the sample in ice bath for 3 minutes ${ }^{12}$. The effect of blanching time and temperature on the activity of peroxidase and polyphenol oxidase, phenolic compounds, anthocyanins, and antioxidant activity (DPPH and ABTS) was evaluated. All analyses were performed in triplicate and in the absence of light.

\section{Preparation of the Enzyme Extract}

The blackberry was mixed with $0.05 \mathrm{M}$ phosphate buffer $(\mathrm{pH} 7.0)$ at $4{ }^{\circ} \mathrm{C}$ in the ratio of 1:5. Subsequently, the suspension was vacuum filtered using Whatman No. 1 filter paper and centrifuged at $1680 \mathrm{~g}$ for 10 minutes at $4{ }^{\circ} \mathrm{C}$, thus obtaining the enzyme extract.

\section{Peroxidase Activity}

The POD activity was determined as described by Hultin et al. ${ }^{13}$. For that, $3 \mathrm{~mL}$ enzyme extract was mixed with $5 \mathrm{~mL}$ phosphate buffer $(0.1 \mathrm{M}, \mathrm{pH} 5.0), 0.5 \mathrm{~mL}$ hydrogen peroxide $(3 \%, \mathrm{v} / \mathrm{v})$ and $0.5 \mathrm{~mL}$ guaiacol. The mixture was incubated at 30 ${ }^{\circ} \mathrm{C}$ for 5 minutes and $1 \mathrm{~mL}$ sodium bisulfite $(30 \%$, w/v) was added to stop the enzymatic reaction. Readings were performed in a UV-visible spectrophotometer (Shimadzu-1800) at $470 \mathrm{~nm}$.

\section{Polyphenoloxidase Activity}

The PPO activity was determined as described by Teisson ${ }^{14}$. A $0.5 \mathrm{~mL}$ aliquot of the enzyme extract was mixed with $1.8 \mathrm{~mL}$ phosphate buffer $(0.05 \mathrm{M}, \mathrm{pH} 7.0)$ and 0.05 $\mathrm{mL}$ catechol $(10 \mathrm{mM})$, and incubated in a water bath at $30{ }^{\circ} \mathrm{C}$ for 30 minutes. A 0.8 $\mathrm{mL}$ aliquot of perchloric acid $(2 \mathrm{~N})$ was added to stop the enzymatic reaction, and readings were performed in UV-visible spectrophotometer (Shimadzu-1800) at 395 nm.

One unit of enzyme activity (Unit) was defined as the absorbance increase of 0.001 units per minute reaction at 470 and $395 \mathrm{~nm}$ for peroxidase and polyphenol oxidase, respectively, under the conditions tested ${ }^{15}$.

\section{Determination of Total Phenolics}

The phenolics content was quantified using the Folin-Ciocalteu reagent ${ }^{16}$. One gram of blanched blackberry was mixed with $10 \mathrm{~mL}$ methanol and subjected to an ultrasonic bath (Ultrasonic Cleaner USC 700) for 10 minutes, filtered in Whatman filter paper N. 1, and transferred to a $25 \mathrm{~mL}$ volumetric flask and the volume was made up with methanol. Next, $500 \mu \mathrm{L}$ was mixed with $10 \mathrm{~mL}$ distilled water, $500 \mu \mathrm{L}$ methanol and $500 \mu \mathrm{L}$ Folin-Ciocalteu reagent and the mixture was allowed to react for 3 minutes. Afterwards, $1.5 \mathrm{~mL}$ sodium carbonate was added $(20 \%, \mathrm{w} / \mathrm{v})$ and allowed to stand for two hours. The reading was performed in UV-visible spectrophotometer (Shimadzu-1800) at $765 \mathrm{~nm}$, and methanol was used as a blank. The results were expressed in mg of gallic acid equivalent (GAE) per 100g of fresh weight.

\section{Determination of Anthocyanins}

The total anthocyanin content was determined using the $\mathrm{pH}$-differential method ${ }^{17}$. The fruit was mixed with $\mathrm{KCl}$ buffer $(0.025 \mathrm{M}, \mathrm{pH} 1.0)$ and $\mathrm{CH}_{3} \mathrm{COONa}(0.4 \mathrm{M}, \mathrm{pH}$ 4.5) at a ratio of 1:90. The absorbance (A) was measured in UV-visible 
spectrophotometer (Shimadzu-1800) at 520 and $700 \mathrm{~nm}$, and the results were calculated according to the equation:

$A=\left(A_{520}-A_{700}\right)_{p H 1.0}-\left(A_{520}-A_{700}\right)_{p H 4.5}$

(1)

where $A_{520}$ is the absorbance at $520 \mathrm{~nm}$ and $A_{700}$ the absorbance at $700 \mathrm{~nm}$.

The concentration of monomeric anthocyanins was calculated according to the equation (2):

$$
M A=\frac{A \times M \times D F \times 100}{\varepsilon \times l}
$$

where: $M$ is the molar mass of cyanidin-3-glucoside $\left(449.2 \mathrm{~g} \cdot \mathrm{mol}^{-1}\right), D F$ is the dilution factor, $\varepsilon$ is the molar extinction coefficient $\left(26900 \mathrm{~L} \cdot \mathrm{mol}^{-1} \cdot \mathrm{cm}^{-1}\right)$ and $l$ is the optical path of the cuvette $(1 \mathrm{~cm})$. The final anthocyanin concentration was expressed in $\mathrm{mg}$ of cyanidin-3-glucoside per 100g of fresh weight.

\section{Determination of Antioxidant Activity}

For the extraction of antioxidant compounds, $2 \mathrm{~g}$ and $9 \mathrm{~g}$ sample were weighed for the DPPH and ABTS assays, respectively, and $40 \mathrm{~mL}$ methanol $(50 \%, \mathrm{v} / \mathrm{v})$ were added and allowed to stand for 60 minutes at room temperature. Shortly after, the mixture was centrifuged (Sigma $4 \mathrm{k} 15$ ) at $18500 \mathrm{~g}$ for 15 minutes and the supernatant was transferred to a $100 \mathrm{~mL}$ volumetric flask. Then, $40 \mathrm{~mL}$ acetone $(70 \% \mathrm{v} / \mathrm{v})$ were added to the residue generated in the previous extraction, and allowed to stand for a further 60 minutes, prior to centrifugation under the same conditions. The supernatant was transferred into a volumetric flask containing the first supernatant and the volume was made up to $100 \mathrm{~mL}$ with distilled water.

DPPH (2,2-diphenyl-1-picryl hydrazyl)

The DPPH assay was performed according to the method described by BrandWilliams et al. ${ }^{18}$. To reach the concentration of $60 \mu \mathrm{M} \mathrm{DPPH}, 2.4 \mathrm{mg}$ DPPH was dissolved in $100 \mathrm{~mL}$ methanol. The solution was homogenized and transferred into dark bottles and used only in the day of analysis. A $0.1 \mathrm{~mL}$ aliquot was transferred to a test tube containing $3.9 \mathrm{~mL}$ DPPH solution and homogenized. A solution $(0.1 \mathrm{~mL})$ composed of methanol $(50 \%, \mathrm{v} / \mathrm{v})$, acetone $(70 \% \mathrm{v} / \mathrm{v})$ distilled water, and $3.9 \mathrm{~mL}$ DPPH solution was used as control. After 45 minutes, the scavenging activity was measured in spectrophotometer at $515 \mathrm{~nm}$, using methanol as a blank. The results were expressed as the percentage of radical sequestration:

$\%=1-\left(\frac{A_{\text {sample }}}{A_{\text {control }}}\right) \times 100$

where $A_{\text {sample }}$ and $A_{\text {control }}$ represent the absorbance of the sample and the control, respectively.

\section{Capture of radical ABTS ${ }^{+}$(2,2'-azinobis-(3-ethyl-benzothiasoline-6- sulfonic acid)}

The antioxidant activity by ABTS was determined as described by Re et al. ${ }^{19}$. The ABTS radical was produced through a reaction between the ABTS stock solution (7 $\mathrm{mM})$ and potassium persulfate (140 $\mathrm{mM}$ final concentration). This mixture was kept in the dark for $12 \mathrm{~h}$ at room temperature before use. For the assay, the ABTS solution was diluted with phosphate buffer $(5 \mathrm{mM}, \mathrm{pH} 7.0)$ until the absorbance of $0.7( \pm 0.02)$ 
at $734 \mathrm{~nm}$ was reached. Aliquots of $10 \mu \mathrm{L}$ sample were mixed with $1 \mathrm{~mL}$ diluted ABTS solution and the absorbance $(734 \mathrm{~nm})$ was measured after 6 minutes. The results were expressed as the percentage of radical sequestration according to Eq. (3).

\section{Calculation of Kinetic Parameters}

To assess the inactivation kinetics of peroxidase and polyphenol oxidase, an inactivation biphasic model was used, consisting of a heat-labile and a heat-resistant fraction, both with first order inactivation kinetics ${ }^{20}$, according to the Equation:

$$
y=a_{L} \exp ^{-k_{L} t}+b_{\mathrm{R}} \exp ^{-k_{R} t}
$$

where $k_{L}$ e $k_{R}$ are the rate constants of labile and heat-resistant component respectively, $a_{L}$ and $b_{R}$ are the model parameters, and $t$ is the blanching time.

A biphasic kinetic model was also used to fit the experimental data of the phenolic compounds (Equation 4).

For anthocyanins and antioxidant activity, a first order kinetic model was used to fit the experimental data, according to Equation (5):

$$
\mathrm{y}=y_{0} \exp (-k t)
$$

where $\mathrm{y}$ is the residual activity and antioxidant activity of anthocyanins, $y_{0}$ is the residual activity of anthocyanins and antioxidant activity at time zero, $k$ is the rate constant, and $t$ is time.

\section{Statistical Analysis}

The results were analyzed by ANOVA, Tukey's multiple comparisons test and Pearson correlation analysis. The software SAS 9.3 (SAS Institute Inc.) was used for statistical trials. Non-linear regression analysis was used for estimating the kinetic model parameters using the Marquardt-Levenberg algorithm from Sigma Plot 8.0 software.

\section{RESULTS AND DISCUSSION}

\section{Inactivation of Peroxidase and Polyphenoloxidase Enzymes}

The peroxidase and polyphenol oxidase activities in the blackberry extract as a function of blanching time are shown in Figures 1A and 1B. The POD and PPO activity decreased with increasing blanching time and temperature. The higher rates of residual activity were found in the first two minutes. Then, the rate of activity remained decreasing slowly until 10 minutes of blanching. This behavior suggests the presence of at least two isoenzymes with different thermal stabilities, one fraction being heat labile which was completely inactivated during the first 2 minutes for both enzymes, and other being heat resistant that cannot be completely inactivated for the time used in blanching.

The reduction in peroxidase activity was not significantly different ( $>0.05)$ after 4 minutes at $80{ }^{\circ} \mathrm{C}$, and after 8 minutes of blanching in water at $90{ }^{\circ} \mathrm{C}$ and in steam. Furthermore, a significant effect of temperature on the enzymatic activity was observed $(\mathrm{p}<0.05)$. The percentage of peroxidase inactivation was $21.90,30.32$, and $71.33 \%$ for blanching in water at $80{ }^{\circ} \mathrm{C}$ and $90{ }^{\circ} \mathrm{C}$ and in steam, respectively. 

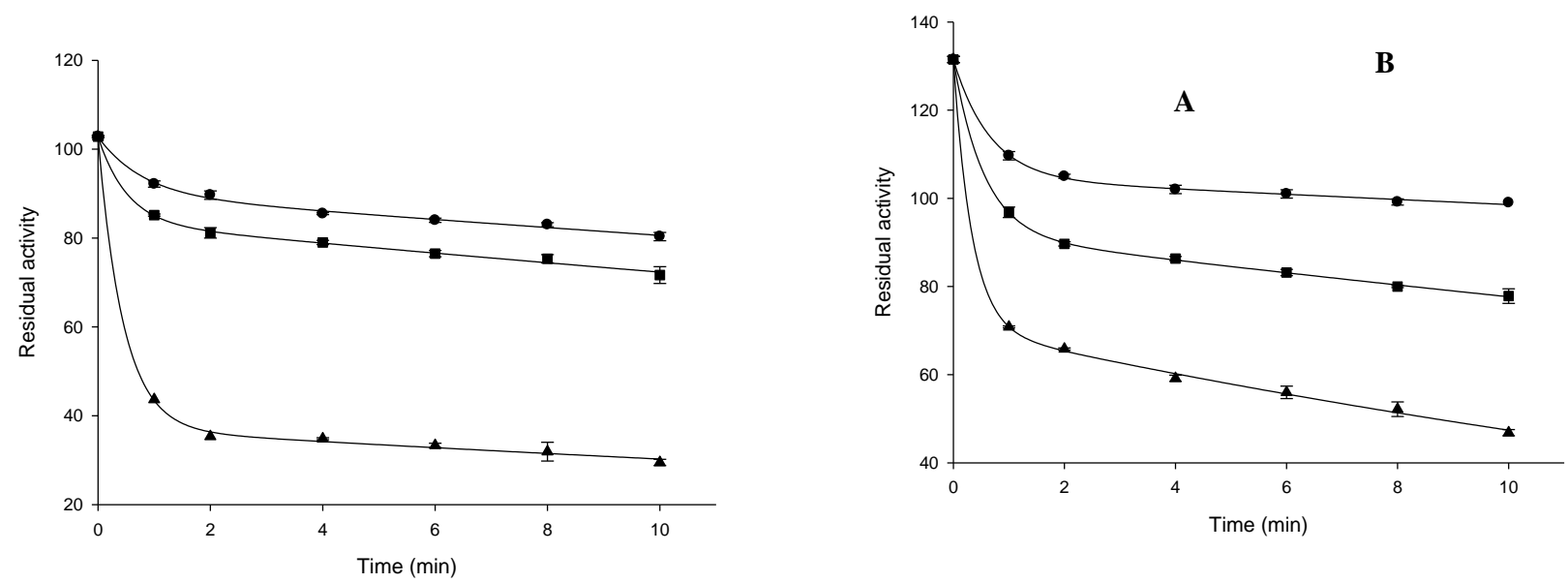

Figure 1. Loss of peroxidase (A) and polyphenol oxidase (B) activity in blackberry (Unit $\mathrm{g}^{-1}$ sample) as a function of time at different temperatures. $(\bullet)$ water $80^{\circ} \mathrm{C} ;(\boldsymbol{\bullet})$ water $90^{\circ} \mathrm{C} ;(\boldsymbol{\Delta})$ steam $100^{\circ} \mathrm{C} ;(\ldots)$ Biphasic model Eq. (4).

Regarding polyphenoloxidase, although the enzyme activity did not decrease significantly ( $>>0.05$ ) after 6 minutes at $80{ }^{\circ} \mathrm{C}$, and after 8 minutes at $90{ }^{\circ} \mathrm{C}$, a significant decreased with time was observed for blanching in steam. In addition, the high temperature resulted in a significant $(\mathrm{p}<0.05)$ decrease in enzyme activity. The percentage inactivation after blanching was relatively low, 24.72, 40.82, and 64.39\% for blanching in water at 80 and $90{ }^{\circ} \mathrm{C}$ and in steam, respectively. It is also important to mention that different authors have suggested the reactivation of enzymes POD and PPO after heating. The ability to recover their activity was especially observed in high-temperature short time treatment, and this possibility of reactivation depends on the method of heat treatment used, the vegetable and the type of isoenzyme ${ }^{21}$.

\section{Phenolic Compounds and Anthocyanins}

The original total phenolics content in blackberry was $761.21 \mathrm{mg}$ (GAE)/100g. The effects of blanching temperature and time on phenolics in blackberry can be seen in Figure 2A. The phenolics content decreased significantly $(\mathrm{p}<0.05)$ with increasing temperature, with no significant difference $(p>0.05)$ from 6 minutes for all temperatures. In addition to the heat sensitivity of phenolic compounds, water blanching induces significant changes in phenolics content due to diffusion and/or leaching.

The percentage degradation of total phenolics was $23.48,29.14$, and $38.5 \%$ at the end of the blanching treatment in water at 80 and $90{ }^{\circ} \mathrm{C}$, and in steam, respectively. 

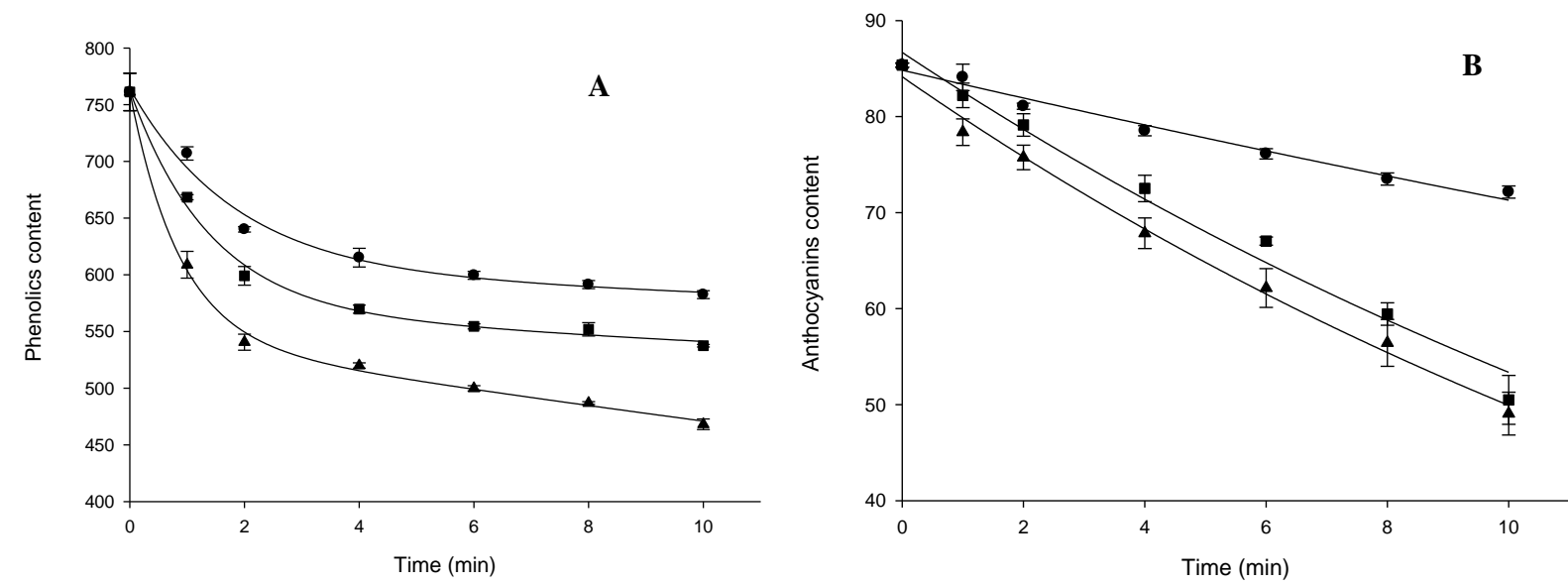

Figure 2. Degradation of phenolic compounds (mg (GAE)/100g) (A) and anthocyanins (mg cyanidin 3glucoside/100g) (B) in blackberry as a function of time at different temperatures. $(\bullet)$ water $80^{\circ} \mathrm{C}$; (घ) water $90^{\circ} \mathrm{C}$; ( $\mathbf{\Delta})$ steam $100^{\circ} \mathrm{C}$; (_ $)$ Biphasic model Eq. (4) and First order model Eq. (5), respectively.

Concerning the anthocyanins, the original content on blackberry was $85.36 \mathrm{mg} / 100 \mathrm{~g}$. Figure 2B shows the anthocyanins degradation during blanching. At $80{ }^{\circ} \mathrm{C}$, the anthocyanins levels have not decreased expressively as observed at $90{ }^{\circ} \mathrm{C}$ and steam, with no significant difference ( $p>0.05$ ) from 8 to 10 minutes. At $90{ }^{\circ} \mathrm{C}$ and steam, a significant difference $(\mathrm{p}<0.05)$ was observed in all blanching times, with more degradation at higher temperatures, which is the main factor of bioactive compound degradation ${ }^{22}$. Furthermore, cyanidin-3-glucoside can be co-oxidized with other phenolic compounds by the polyphenol oxidase, forming 0 -quinones that generate polymerized products by quinone-phenol reactions ${ }^{23}$.

\section{Antioxidant Activity (DPPH and ABTS)}

The initial antioxidant activity of blackberry was $67.8 \%$ by DPPH assay and $82.8 \%$ by ABTS, which decreased with increasing time and temperature, as can be seen in Figures $3 \mathrm{~A}$ and $3 \mathrm{C}$. The percentages obtained in DPPH and ABTS assays can be explained by the distinct stereoselectivity of the radicals, different compounds in the sample that can react and eliminate various radicals ${ }^{24}$. Therefore, a greater activity obtained by the ABTS method does not necessarily imply in high sequestration capacity of the DPPH radicals ${ }^{25}$.

A significant loss $(\mathrm{p}<0.05)$ of antioxidant activity during blanching until 6 minutes at 80 and $90{ }^{\circ} \mathrm{C}$ was observed by DPPH assay. In steam, significant loss was observed $(p<0.05)$ during the whole time. When comparing the different treatments, significant losses were observed for blanching $(\mathrm{p}<0.05)$ in steam rather than in water at 80 and 90 ${ }^{\circ} \mathrm{C}$.

After 10 minutes of heating, losses of $38.96 \%, 47.94 \%$, and $74.4 \%$ in water at 80 and $90{ }^{\circ} \mathrm{C}$ and in steam, respectively, were observed for the antioxidant activity by DPPH assay.

No significant differences in the antioxidant activity by ABTS ( $>>0.05)$ were observed from 8 to 10 minutes at $90^{\circ} \mathrm{C}$ and steam (Figure 3B), while a significant degradation $(p<0.05)$ was observed at $80^{\circ} \mathrm{C}$ for all blanching times. With respect to the effect of temperature, significant differences $(\mathrm{p}<0.05)$ were observed between the three blanching temperatures. 
When comparing both methods, the degradation of the antioxidant activity by ABTS radical was lower than that observed in DPPH, with losses of $13.3 \%, 16.5 \%$, and $24.5 \%$ in water at 80 and $90^{\circ} \mathrm{C}$ and in steam, respectively.
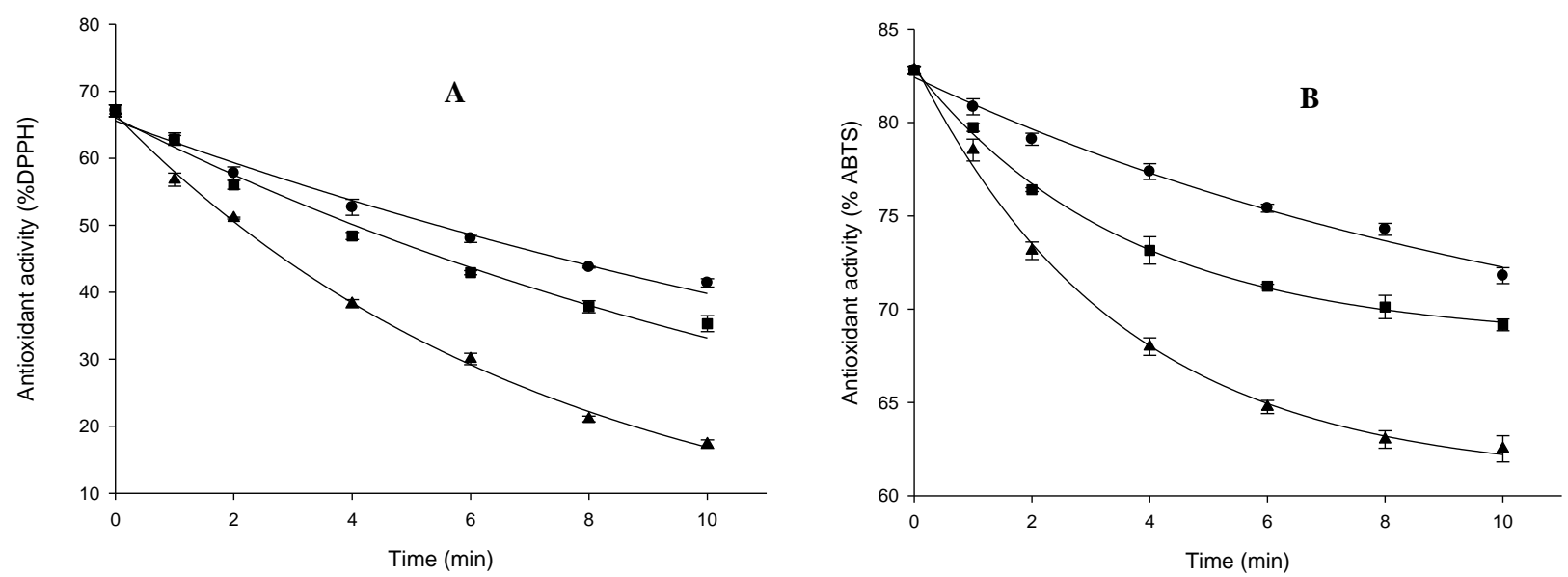

Figure 3. Loss of antioxidant activity with DDPH (A) and ABTS (B) in blackberry as a function of time at different temperatures. $(\bullet)$ water $80^{\circ} \mathrm{C} ;(\mathbf{\square})$ water $90^{\circ} \mathrm{C} ;(\mathbf{\Delta})$ steam $100^{\circ} \mathrm{C} ;\left(\_\right)$First order model Eq. (5).

\section{Inactivation Kinetics of Peroxidase and Polyphenol Oxidase}

The inactivation kinetics of peroxidase and polyphenol oxidase was calculated by the two-phase model. The reaction rate constants, correlation coefficients, and activation energy are shown in Table 1.

The results of the regression analysis provided data adjusted to two-phase model, with $\mathrm{R}^{2}$ greater than 0.995 for all temperatures. The biphasic model indicates the presence of isozymes with distinct stability, allowing separation into two different groups, one component being heat labile and the other heat resistant, both following the first order kinetics ${ }^{20}$. According to some authors, POD thermal inactivation kinetic studies at 70 to $100^{\circ} \mathrm{C}$ usually occur in biphasic cycles ${ }^{20}$. Goyeneche et al. ${ }^{26}$ have also demonstrated the enzyme kinetics described by the two-phase model in radish PPO inactivated at temperatures of 60 to $90^{\circ} \mathrm{C}$.

Significant differences were observed for $k_{L}$ and $k_{R}$ values of both enzymes $(\mathrm{p}<0.05)$, which increased with increasing temperature as observed in several studies as polyphenoloxidase in radish ${ }^{26}$, and peroxidase in asparagus ${ }^{27}$. The $k$ values of the heat-labile fractions were higher than those of the heat-resistant fractions, as reported by Morales-Blancas et al. ${ }^{27}$ in a kinetic degradation of peroxidase and lipoxygenase in broccoli, asparagus and carrot, and by Fante and Noreña ${ }^{12}$ on the enzymatic inactivation of peroxidase, polyphenol oxidase and inulinase during blanching of garlic. 
Table 1. Reaction rate constants of peroxidase, polyphenoloxidase, phenolic compounds, anthocyanins and antioxidant activity of blackberry in different blanching conditions.

\begin{tabular}{cccc}
\hline $\boldsymbol{T}\left({ }^{\circ} \mathrm{C}\right)$ & $\boldsymbol{k}_{\boldsymbol{L}}\left(\mathrm{min}^{-1}\right)$ & $\boldsymbol{k}_{\boldsymbol{R}}\left(\mathrm{min}^{-1}\right)$ & $\boldsymbol{R}^{\mathbf{2}}$ \\
\hline Peroxidase & & & \\
80 & $1.266 \pm 0.107^{\mathrm{a}}$ & $0.010 \pm 0.001^{\mathrm{a}}$ & 0.995 \\
90 & $1.953 \pm 0.280^{\mathrm{b}}$ & $0.014 \pm 0.001^{\mathrm{b}}$ & 0.997 \\
100 & $2.223 \pm 0.195^{\mathrm{c}}$ & $0.020 \pm 0.005^{\mathrm{c}}$ & 0.999 \\
Polyphenoloxidase & & & \\
80 & $1.517 \pm 0.128^{\mathrm{a}}$ & $0.006 \pm 0.001^{\mathrm{a}}$ & 0.999 \\
90 & $1.836 \pm 0.082^{\mathrm{b}}$ & $0.016 \pm 0.001^{\mathrm{b}}$ & 0.999 \\
100 & $3.012 \pm 0.252^{\mathrm{c}}$ & $0.039 \pm 0.002^{\mathrm{c}}$ & 0.999 \\
& & & \\
Phenolic Compounds & & $0.003 \pm 0.000^{\mathrm{a}}$ & 0.987 \\
90 & $0.547 \pm 0.017^{\mathrm{a}}$ & $0.005 \pm 0.000^{\mathrm{b}}$ & 0.995 \\
100 & $0.721 \pm 0.047^{\mathrm{b}}$ & $0.014 \pm 0.003^{\mathrm{c}}$ & 0.998
\end{tabular}

\begin{tabular}{ccc}
\hline $\boldsymbol{T}\left({ }^{\circ} \mathrm{C}\right)$ & $\boldsymbol{k}\left(\mathrm{min}^{-1}\right)$ & $\boldsymbol{R}^{\mathbf{2}}$ \\
\hline Anthocyanins & & 0.982 \\
80 & $0.017 \pm 0.001^{\mathrm{a}}$ & 0.982 \\
90 & $0.048 \pm 0.003^{\mathrm{b}}$ & 0.994 \\
100 & $0.052 \pm 0.002^{\mathrm{c}}$ & \\
DPPH & & 0.984 \\
80 & $0.050 \pm 0.003^{\mathrm{a}}$ & 0.985 \\
90 & $0.069 \pm 0.004^{\mathrm{b}}$ & 0.998 \\
100 & $0.137 \pm 0.003^{\mathrm{c}}$ & \\
$\boldsymbol{A B T S}$ & & 0.988 \\
80 & $0.085 \pm 0.012^{\mathrm{a}}$ & 0.998 \\
90 & $0.277 \pm 0.020^{\mathrm{b}}$ & 0.997 \\
100 & $0.285 \pm 0.027^{\mathrm{c}}$ & \\
\hline
\end{tabular}

$k_{L}$ and $k_{R}$ : constant of thermal inactivation of heat-labile and heat-resistant fractions, respectively.

$k$ : thermal degradation constant

Same lowercase letters in the same column indicate no significant difference ( $p>0.05)$.

With respect to the rate constants of the enzymes, the PPO labile fraction at $90{ }^{\circ} \mathrm{C}$ and the heat resistant fraction at $80^{\circ} \mathrm{C}$ presented grater resistance when compared to POD. Fante and Noreña ${ }^{12}$ also reported that polyphenol oxidase is more heat resistant than peroxidase in blanched garlic slices. Terefe et al. ${ }^{28}$ studied polyphenol oxidase inactivation of mashed strawberries, and found a highly thermostable behavior without significant inactivation after 30 minutes at $100^{\circ} \mathrm{C}$ under atmospheric pressure. According to these authors, the thermostability of polyphenol oxidase is not common in plant tissues, but depends on the fruit species and cultivar. A possible contributing factor would be the activation of latent polyphenol oxidase, which can be activated by different treatments such as exposure to detergents, acidic $\mathrm{pH}$, unsaturated fatty acids, proteases, and heat ${ }^{29,30}$. These different treatments activate the latent PPO through conformational changes that eliminate the polypeptide that protects the active site of the enzyme ${ }^{30}$. In this study, the heat treatment is the main factor for activation of the latent form of the enzyme. Yemenicioglu et al. ${ }^{29}$ observed that the PPO activity was three times higher in some apple cultivars after 15 minutes of blanching in water at 68 ${ }^{\circ} \mathrm{C}$ due to activation of latent polyphenol oxidase.

\section{Degradation Kinetics of Phenolic Compounds}

Several authors have reported that the phenolic compounds degradation kinetics follows the zero order or first order model. However, our experimental data did not 
properly fit these models. However, the data fitted well by the biphasic model, and the reaction rate constants, correlation coefficients, and activation energy are given in Table 1.

The inactivation constants $k_{\mathrm{L}}$ and $k_{\mathrm{R}}$ were significantly different with temperature $(\mathrm{p}<0.05)$, and the $k$ values increased with increasing temperature. The biphasic model indicates the presence of compounds resistant to high temperatures. Phenolics in blackberry belonging to the class of flavonoids ${ }^{31}$, especially catechins ${ }^{32}$, epicatechins ${ }^{33}$, and epigallocatechin ${ }^{34}$ have a higher thermal stability than the other phenolic compounds. The different thermal stability of flavonoids may be due to the number and arrangement of hydroxyl groups in the chains of such compounds ${ }^{35}$.

\section{Anthocyanins Degradation Kinetics and Antioxidant Activity}

The rate constants and the activation energy of anthocyanins degradation and antioxidant activity of blackberry are shown in Table 1 .

The estimated kinetic parameters for the anthocyanins degradation and antioxidant activity followed the first-order model, with good agreement with $R^{2}$ values greater than 0.982. Some studies showed that the thermal degradation of anthocyanins also followed first order kinetics in strawberry at 80 to $130^{\circ} \mathrm{C}$ with $k$ ranging from 0.007 to $0.11 \mathrm{~min}^{-136}$, and raspberry at 90 to $110^{\circ} \mathrm{C}$ with $k$ ranging from 0.049 to $0.206 \mathrm{~min}^{-1} 37$. It was also observed that the rate constant increased significantly $(p<0.05)$ with temperature from 0.017 to $0.052 \mathrm{~min}^{-1}$. Reyes and Cisneros- Zevallos ${ }^{38}$ studied the anthocyanins degradation kinetics in grape at 25 to $98^{\circ} \mathrm{C}$, and found that the $\mathrm{k}$ values increased from 0.0006 to $0.2853 \mathrm{~min}^{-1}$ with increasing blanching temperature.

The antioxidant activity (DPPH and ABTS) also followed the first order kinetic model, showing a good fit of the experimental data $\left(R^{2}\right.$ higher than 0.984$)$ and $k$ values increased significantly $(\mathrm{p}<0.05)$ with increasing temperature. The $k$ values ranged from 0.050 to $0.137 \mathrm{~min}^{-1}$ by DPPH assay, and from 0.085 to $0.285 \mathrm{~min}^{-1}$ by ABTS. Jaiswal et al. ${ }^{11}$ studied the degradation kinetics of the antioxidant activity by DPPH assay in cabbage subjected to temperatures of 80 to $100^{\circ} \mathrm{C}$, and found that the $k$ values increased from 0.159 to $0.186 \mathrm{~min}^{-1}$ with increasing blanching temperature.

\section{Pearson Correlation Analysis}

Table 2 shows that total phenolic and anthocyanin contents had a strong positive correlation to both DPPH and ABTS antioxidant activities (correlation coefficients higher than 0.90). These results provide strong evidence that the source of the antioxidant activity is derived from the phenolic compounds. Positive correlation between antioxidant activity with anthocyanin content were also reported in blackberry ${ }^{3}$, and in blueberries and grapes ${ }^{39}$. The phenolic compounds, where are included anthocyanins, phenolic acids, catechins and flavonols, exhibit high antioxidant capacity ${ }^{40}$. In the same way, phenolics and anthocyanins also had a high correlation with both PPO and POD enzymes (values between 0.83 and 0.89). The presence of PPO and POD, which were not totally inactivated during blanching, are related with degradation of anthocyanins ${ }^{41}$. In addition, during blanching others enzymes must be deactivated. It has been postulated that anthocyanin- $\beta$-glucosidase may remove the sugar from anthocyanins to form anthocyanidins, which might be oxidized by POD and PPO in the presence of phenolic compounds ${ }^{42}$.

This study was important because it helps in the correct design of unit operation of blanching. Therefore, it was necessary to know the kinetic models that allow predicting the changes of quality in blackberry at different combination of time and temperature. 


\section{CONCLUSIONS}

During blanching of blackberry, the inactivation of the enzymes peroxidase and polyphenol oxidase and the degradation of phenolic compounds were adequately adjusted to the two-phase model, with $R^{2}$ greater than 0.995 . The first order kinetic model was used to predict the kinetic behavior of the antioxidant activity and anthocyanin content. In all cases, an increase in the rate constants with increasing temperature from 80 to $100^{\circ} \mathrm{C}$ was observed. The percentages of inactivation of the enzymes POD and PPO and the losses of polyphenols and anthocyanins increased with temperature. The difficulty of using shorter blanching times was due to the presence of heat resistant enzymatic fractions of POD and PPO.

Table 2. Pearson correlation coefficients between total phenolic and anthocyanin contents, DPPH and ABTS antioxidant activities, and peroxidase and polyphenol oxidase enzymes during blanching of blackberry

\begin{tabular}{lcccccc}
\hline & PPO & POD & Phenolics & Anthocyanins & DPPH & ABTS \\
\hline PPO & 1.000 & & & & & \\
POD & 0.960 & 1.000 & & & & \\
Phenolics & 0.833 & 0.834 & 1.000 & & & \\
Anthocyanins & 0.890 & 0.890 & 0.852 & 1.000 & & \\
DPPH & 0.912 & 0.918 & 0.900 & 0.920 & 0.977 & 1.000 \\
ABTS & 0.868 & 0.897 & 0.925 & 0.915 & 000 \\
\hline
\end{tabular}

\section{ACKNOWLEDGEMENTS}

This work was supported by FAPERGS, CAPES and CNPq, Brazil.

\section{REFERENCES}

1. Siriwoharn T, Wrolstad RE, Finn CE, Pereira CB. Influence of cultivar, maturity, and sampling on blackberry (Rubus L. Hybrids) anthocyanins, polyphenolics, and antioxidant properties. J Agric Food Chem. 2004; 52: 8021-8030.

2. Moyer RA, Hummer KE, Finn CE, Frei B, Wrolstad RE. Anthocyanins, phenolics, and antioxidant capacity in diverse small fruits: vaccinium, rubus, and ribes. J Agric Food Chem. 2002; 50: 519-525.

3. Fan-Chiang HJ, Wrolstad RE. Anthocyanin pigment composition of blackberries. J Food Sci. 2005; 70: C198-C202.

4. Wang H, Cao G, Prior RL. Oxygen radical absorbing capacity of anthocyanins. J Agric Food Chem. 1997; 45: 304-309.

5. Renaud S, De Lorgeril M. Wine, alcohol, platelets, and the French paradox for coronary heart disease. Lancet. 1992; 339: 1523-1526.

6. Francis FJ. Food colorants: anthocyanins. Crit Rev Food Sci Nutr. 1989; 28: 273-314.

7. Hemeda HM, Klein BP. Effects of naturally occurring antioxidants on peroxidase activity of vegetable extracts. J Food Sci. 55; 1990: 184-187.

8. Soysal C, Söylemez Z. Kinetics and inactivation of carrot peroxidase by heat treatment. $J$ Food Eng. 2005; 68: 349-356.

9. Mc Evily AJ, Iyengar R. Inhibition of enzymatic browning in foods and beverages. Crit Rev Food Sci Nutr. 1992; 32: 253-273.

10. Markakis P. Anthocyanins and their stability in foods. Crit Rev Food Technol. 1974; 4: 437-341.

11. Jaiswal KA, Gupta S, Ghannam N. Kinetic evaluation of colour, texture, polyphenols and antioxidant capacity of Irish York cabbage after blanching treatment. Food Chem. 2012; 131: $63-72$. 
12. Fante L, Noreña CPZ. Enzyme inactivation kinetics and colour changes in garlic (Allium sativum L.) blanched under different conditions. J Food Eng. 2012; 108: 436-443.

13. Hultin HO, Sun B, Bulger J. Pectin methyl esterases of the banana: purification and properties. J Food Sci. 1966; 31: 320-327.

14. Teisson C. Le brunissement interne de 1 ananás. I-Historique. II Material et méthodes. Fruit. 1979; 34: 245-281.

15. Sun N, Song K. Effect of nonthermal treatment on the molecular properties of mushroom polyphenoloxidase. J Food Sci. 2003; 68:1639-1643.

16. Singleton VL, Rossi JA. Colorimetry of total phenolics with phosphomolybdicphosphotungstic acid reagents. Am J Enol Vitic. 1965; 16: 144-158.

17. Giusti MM, Wrolsted RE. Anthocyanins: characterization and measurement with UVvisible spectroscopy. In: Wrolstad RE, Schwartz SJ, editors. Current Protocols in Food Analytical Chemistry, N.Y.: Wiley. 2001; 1-13.

18. Brand-Williams W, Cuvelier ME, Berset C. Use of a free radical method to evaluate antioxidant activity. LWT Food Sci Technol. 1995; 28: 25-30.

19. Re R, Pellegrini N, Proteggente A, Panala A, Yang M, Rice-Evans C. Antioxidant activity applying an improved ABTS radical cation decolorization assay. Free Radical Biol Med. 1999; 26: $1231-1237$.

20. Ling AC, Lund DB. Determining kinetic parameters for thermal inactivation of heatresistant and heat-labile isozymes from thermal destruction curves. J Food Sci. 1978; 43: 1307-1310.

21. Pérez-Calderón J, Califano A, Santos MV, Zaritzky N. Kinetic parameters for the thermal inactivation of peroxidase and lipoxygenase in precooked frozen Brassica species. J Food Sci. 2017; 82: 1378-1386.

22. Wang WD, Xu SY. Degradation kinetics of anthocyanins in blackberry juice and concentrate. J Food Eng. 2007; 82: 271-275.

23. Kader F, Haluk JP, Nicolas JP, Metche M. Degradation of cyanidin 3-glucoside by blueberry polyphenol oxidase: kinetic studies and mechanisms. J Agric Food Chem. 1998; 46: 3060-3065.

24. Zhu YP, Fan J F, Cheng YQ, Li LT. Improvement of the antioxidant activity of Chinese traditional fermented okara (Meitauza) using Bacillus subtilis B2. Food Control. 2008; 19: 654-661.

25. Corrêa APF, Daroit DJ, Coelho J, Meira MMM, Lopes CF, Segalin J, et al. Antioxidant, antihypertensive and antimicrobial properties of ovinemilk caseinate hydrolyzed with a microbial protease. J Sci Food Agric. 2011; 91: 2247-54.

26. Goyeneche R, Scala KD, Roura S. Biochemical characterization and thermal inactivation of polyphenol oxidase from radish (Raphanus sativus var. sativus). LWT Food Sci Technol. 2013; 54: 57-62.

27. Morales-Blancas EF, Chandia VE, Cisneros-Zevallos L. Thermal inactivation kinetics of peroxidase and lipoxygenase from broccoli, green asparagus and carrots. J Food Sci. 2002; 67:146-154.

28. Terefe NS, Yang YH, Knoerzer K, Buckow R, Versteeh C. High pressure and thermal inactivation kinetics of polyphenol oxidase and peroxidase in strawberry puree. Innov Food Sci Emerg Technol. 2010; 11: 52-60.

29. Yemenicioglu A, Ozkan M, Cemeroglu B. Heat inactivation kinetics of apple polyphenoloxidase and activation of its latent form. J Food Sci. 1997; 62: 508-510.

30. Lei DF, Feng Y, Jiang DZ. Characterization of polyphenol oxidase from plants. Prog Nat Sci. 2004; 14: 553-561.

31. Bravo L. Polyphenols: Chemistry, dietary Sources, metabolism, and nutritional significance. Nutr Rev. 1998; 56: 317-333.

32. Tsanova-Savova S, Ribarova F, Gerova M. (+)-Catechin and (-)- epicatechin in Bulgarian fruits. J Food Compos Anal. 2005; 18: 691-698.

33. Jakobek L, Seruga M, Seruga B, Novak I, Medvidovic-Kosanovic M. Phenolic compound composition and antioxidant activity of fruits of Rubus and Prunus species from Croatia. Int $J$ Food Sci Technol. 2009; 44: 860-868.

34. Pascual-Teresa S, Santos-Buelga C, Rivas-Gonzalo JC. Quantitative analysis of flavan-3ols in spanish foodstuffs and beverages. J Agric Food Chem. 2000; 48: 5331-5337. 
35. Rice-Evans CA, Miller JN, Paganga G. Structure-antioxidant activity relationships of flavonoids and phenolic acids. Free Radical Biol Med. 1996; 20: 933-956.

36. Verbeyst L, Oey I, Plancken I, Hendrickx M, Loey AV. Kinetic study on the thermal and pressure degradation of anthocyanins in strawberries. Food Chem. 2010; 123: 269-274.

37. Verbeyst L, Crombruggen KV, Van der Plancken I, Hendrickx M, Loey AV. Anthocyanin degradation kinetics during thermal and high pressure treatments of raspberries. $J$ Food Eng. 2011; 105: 513-521.

38. Reyes LF, Cisneros-Zevallos L. Degradation kinetics and colour of anthocyanins in aqueous extracts of purple- and red-flesh potatoes (Solanum tuberosum L.). Food Chem. 2007; 100: $885-894$.

39. Camire ME, Chaovanalikit A, Dougherty MP, Briggs J. Blueberry and grape antocyanins as breakfast cereal colorants. J Food Sci. 2002; 67: 438-441.

40. Sellappan S, Akoh CC, Krewer G. Phenolic compounds and antioxidant capacity of georgia-grown blueberries and blackberries. J Agric Food Chem. 2002; 50: 2432-2438.

41. Brownmiller C, Howard LR, Prior RL. Processing and storage effects on monomeric anthocyanins, percent polymeric color, and antioxidant capacity of processed blueberry products. J Food Sci. 2008; 73: H72-H79.

42. Zhang Z, Xuequn P, Ji Z, Jiang Y. Role of anthocyanin degradation in litchi pericarp browning. Food Chem. 2001; 75: 217-221. 